\title{
Atividade pozolânica de arenito zeolítico da região Nordeste do Brasil
}

\author{
Pozzolanic activity of zeolite-bearing \\ sandstone from northeast Brazil
}

\section{Marcelo de Souza Picanço \\ M.Sc. em Engenharia Civil, Doutorando da Universidade Federal do Pará, Instituto de Geociências, PPGG. marcelopicanco2004@yahoo.com.br \\ Rômulo Simões Angélica \\ Dr. em Geociências, Professor Associado da \\ Universidade Federal do Pará, \\ Instituto de Geociências, PPGG. \\ angelica@ufpa.br}

\section{Márcio Santos Barata}

Dr. em Geociências,

Universidade Federal do Pará, Instituto de Geociências, PPGG. marciosbarata@yahoo.com.br

\section{Resumo}

No nordeste do Brasil, existe a ocorrência de zeolitas sedimentares relacionadas a arenitos, descoberta nos anos 2000. Esses arenitos são constituídos de quartzo, zeolitas naturais (estilbita) e argilominerais (esmectita). Estudos preliminares constataram que esse arenito pode ser empregado como material pozolânico em sistemas à base de cimento Portland, desde que o material seja peneirado para remoção do quartzo e ativado termicamente, uma vez que a estilbita é zeolita de baixa atividade pozolânica. O objetivo geral desse trabalho foi determinar qual a fração granulométrica que proporciona a maior concentração de zeolita e esmectita e a temperatura de calcinação que acarreta a maior atividade pozolânica.

No programa experimental, empregou-se o arenito zeolítico passante nas peneiras \#200 e \#325 e calcinado às temperaturas de $150^{\circ} \mathrm{C}, 300^{\circ} \mathrm{C}$ e $500^{\circ} \mathrm{C}$. A análise da caracterização mineralógica das amostras peneiradas foi realizada por difração de raios X, por análises termogravimétrica e termodiferencial. Para avaliação da reatividade, foram realizados ensaios mecânicos de atividade pozolânica em argamassas de cal hidratada e cimento Porltand.

Os resultados mostraram que a amostra peneirada na peneira \#200 foi a mais adequada porque apresentou elevada concentração de estilbita e um percentual maior de material passante em comparação a amostra da peneira \#325, 15\% e 2\% respectivamente. A temperatura de calcinação de $500^{\circ} \mathrm{C}$ foi a que proporcionou a maior atividade pozolânica, em razão da modificação mais efetiva da estrutura cristalina, tanto da estilbita, como da esmectita. As temperaturas mais moderadas a $150^{\circ} \mathrm{C}$ e $300^{\circ} \mathrm{C}$ não foram suficientes para a obtenção dos mesmos resultados. As argamassas com $\mathrm{o}$ arenito passante na peneira $\# 200$ e calcinado a $500^{\circ} \mathrm{C}$ atingiram os valores limites mínimos exigidos para que um material seja considerado pozolânico, no caso, $6 \mathrm{MPa}$ para argamassas de cal hidratada e $75 \%$ para o índice de atividade pozolânica (IAP).

Palavras-chave: Pozolana, cimento Portland, arenito, zeolita, estilbita. 
size distribution that yields the highest smectite and zeolite concentration, besides the best temperature for higher pozzolanic activity.

The experimental program employed the zeolitic sandstone passing through a $\# 200$ and \#325 mesh sieve and calcination at the following temperatures: $150^{\circ} \mathrm{C}$, $300^{\circ} \mathrm{C}$ and $500^{\circ} \mathrm{C}$. Chemical analysis of the sieved samples was carried out by X-ray fluorescence spectroscopy and X-ray diffractometry, while mineralogical characterization was done by X-ray and thermogravimetric analysis and thermogravimetry.. To assess reactivity, calorimetry driving and mechanical tests for pozzolanic activity in hydrated lime and cement Porltand were performed.

The results showed that the sample sieved through at \#200 mesh was the most suitable because it had a higher concentration of estilbite and a higher percentage of material seived compared to the sample sieved at \#325 mesh, $15 \%$ and $2 \%$ respectively. The $500^{\circ} \mathrm{C}$ calcination temperature was accompanied by increased pozzolanic activity due to changes in estilbite and smectite cristalinity; the more moderate temperatures of $150^{\circ} \mathrm{C}$ and $300^{\circ} \mathrm{C}$ were not sufficient to achieve similar results.

The mortars with sandstone sieved at $\# 200$ mesh and calcinated at $500^{\circ} \mathrm{C}$ reached the minimum limits required for a material to be considered as pozzolanic, i.e, $6 \mathrm{MPa}$ for hydrated lime mortars and 75\% for the pozzolanic index activity (PAI).

Keywords: Pozzolan, Portland cement, limestone, zeolite, estilbite.

\section{Introdução}

A pozolana é uma adição mineral incorporada ao cimento Portland com o intuito de proporcionar maior durabilidade às argamassas e concretos. Por si só não possui propriedades cimentícias, mas, pelo fato de ser um material silicoso ou aluminossilicoso, finamente dividido, reage na temperatura ambiente com o hidróxido de cálcio (portlandita) - produto resultante das reações de hidratação do clínquer Portland - para formar silicatos de cálcio hidratados, que são os responsáveis pela resistência mecânica do cimento Portland. Além disto, pelo fato de terem a granulometria mais fina que a do cimento, as pozolanas preenchem os espaços vazios na interface aglomeranteagregado, alterando a microestrutura do concreto ou da argamassa. Todos esses efeitos repercutem, normalmente, no aumento da impermeabilidade, da resistência final e da durabilidade do concreto a determinados ataques químicos (Mehta \& Monteiro, 1994).

As pozolanas também reduzem o calor gerado a partir da hidratação do cimento, que, normalmente, ocasiona fissuras de origem térmica. Atribui-se isto ao efeito de diluição da substituição do cimento pela pozolana e ao fato de a reação pozolânica ser lenta e secundária, ocorrendo, somente, a partir das reações de hidratação do cimento, o que faz com que o calor seja diluído ao longo de um maior intervalo de tempo (Malhotra \& Metha, 1996).

Outro aspecto favorável da incorporação de pozolanas ao cimento Por- tland é a redução na utilização de boa parte da matéria-prima, principalmente o calcário, possibilitando, não somente uma economia desse insumo, como também obterem-se reduções substanciais no consumo de energia e, principalmente, na liberação de $\mathrm{CO}_{2}$ para a atmosfera, uma vez que esses materiais são incorporados em teores que variam entre 14 e 50\% sobre a massa de cimento (Barata, 2007).

De modo geral, as pozolanas são oriundas de depósitos naturais, ou resultantes de subprodutos industriais ou produzidas artificialmente. As pozolanas naturais procedem de ambientes geológicos distintos, como os depósitos piroclásticos, cujos materiais são enriquecidos com fases vítreas, assim como os produtos das suas alterações secundárias como os vidros alterados por processos hidrotermais e as zeólitas. Além destes, sedimentos clásticos como cherts, diatomitas, entre outros, são considerados depósitos naturais de pozolanas. No grupo dos subprodutos industriais, destacam-se as escórias de alto-forno granuladas e outras resfriadas rapidamente, as cinzas volantes resultantes da combustão do carvão mineral (lignito ou antracito), a sílica ativa (resíduo da indústria de produção do silício metálico), a cinza de casca de arroz, entre outras. As pozolanas produzidas artificialmente possuem grande interesse industrial, quando se pretende obter propriedades de qualidade superior ou quando não há disponibilidade de pozolanas naturais ou subprodutos industriais. São elas as argilas e as rochas vulcânicas ativadas termicamente, como o metacaulim e as piçarras e margas calcinadas (Barata, 2007).

Dentro desse contexto de redução energética, as zeólitas são materiais interessantes do ponto de vista econômico e ambiental, porque, na sua grande maioria, não necessitam de tratamento térmico para adquirirem atividade pozolânica e, geralmente, podem ser incorporadas entre 5 e $20 \%$ ao cimento Portland. Cerca de $95 \%$ das zeólitas naturais podem ser utilizadas como material ativo na produção de cimento Portland pozolânico, com destaque para a crinoptilonita, phillipsita, herschelita e a analcima, entre outras. A reatividade das zeólitas está associada a sua composição química e à complexidade de sua estrutura cristalina. A relação Si/Al baixa, a maior concentração de cátions trocáveis $\left(\mathrm{Na}^{+}, \mathrm{K}^{+}\right.$, $\mathrm{Mg}^{2+}$ ), a presença de $\mathrm{Al}^{3+}$ na estrutura do retículo cristalino em substituição ao $\mathrm{Si}^{4+}$, menores concentrações de $\mathrm{Ca}^{2+}$ e um sistema interno favorável de passagem e vazios nos canais e cavidades da estrutura da zeólita são os fatores que determinam a maior atividade pozolânica com o hidróxido de cálcio (Jiexiang \& Suren, 1993; Luz, 1995).

No Brasil, até o presente momento, não existem depósitos naturais de zeólitas conhecidos que possam ser explorados comercialmente para a fabricação de cimento, ou para qualquer outra aplicação industrial. Contudo, nos anos 1990, foi descoberta, na bacia do Parnaíba, uma ocorrência de zeolita sedimentar, do tipo 
predominantemente estilbita, associada a arenitos pertencentes à Formação Corda. Essa ocorrência é bastante extensa, localizada nos arredores da cidade de Imperatriz, estendendo-se até o Estado de Tocantins (Rezende \& Angélica, 1999). As propriedades pozolânicas dessa zeolita foram, primeiramente, investigadas por pesquisadores da Universidade Politécnica de Madri, por meio da técnica de condutividade elétrica. Concluiu-se que a estilbita da bacia do Parnaíba possui baixa atividade pozolânica, em razão da sua composição química, do alto teor de quartzo e da presença do $\mathrm{Ca}^{2+}$, que reduz a capacidade de troca catiônica (Mustelier, 2008).

Picanço et al., (2011), em trabalho de investigação preliminar, realizado recentemente no Brasil, sobre o mesmo material, apontaram para o fato de que os arenitos da bacia do Parnaíba, quando peneirados, apresentaram atividade pozolânica devido à presença da estilbita, contudo, incipiente para atender aos cri-

\section{Materiais e métodos}

Nesse programa experimental, foi utilizada a mesma amostra. Ainda, no referido programa, foram utilizados os mesmos procedimentos de preparação do arenito zeolítico da bacia do Paraíba, pertencente à Formação Corda, estudado no trabalho preliminar de investigação (Picanço et al., 2011). A amostra foi coletada no campo, secada ao ar, desagregada e moída por 2 horas em moinho de bolas. Em seguida, a amostra foi passada nas peneiras \#100 (AZ1), \#200 (AZ2) e \#350 (AZ3), sendo o material passante aproveitado para a análise. Nesse trabalho, investigaram-se apenas as amostras AZ2 e AZ3, uma vez que o material passante na peneira \#100, apesar da sua quantidade ser elevada em relação à amostra total (70\%), apresentou uma concentração muito elevada de quartzo, mineral inerte do ponto de vista da atividade pozolânica, o que inviabiliza sua aplicação como pozolana. Os volumes dos materiais passantes, em relação à massa total das amostras AZ2 e AZ3,

Tabela 1

Nomenclatura das amostras analisadas. térios de produção de cimento. Todavia, como o arenito zeolítico é constituído não somente de estilbita, mas, também, de esmectita, a pesquisa concluiu que, se esse material for calcinado a temperaturas moderadas (até $500^{\circ} \mathrm{C}$ ), o tratamento térmico poderá incrementar a sua atividade pozolânica, em razão do desordenamento parcial das estruturas cristalinas, tanto da estilbita, quanto da esmectita (Picanço et al., 2011).

A pesquisa anteriormente citada faz parte de um projeto de pesquisa mais amplo conduzido pelo Grupo de Mineralogia Aplicada do Instituto de Geociências da Universidade Federal do Pará, que visa a encontrar uma aplicabilidade industrial a essas zeólitas sedimentares, que já foram amplamente estudadas e caracterizadas do ponto de vista geológico, mas não do ponto de vista industrial. Esses depósitos apresentam grande potencial de aplicação em termos de logística, devido à proximidade da ocorrência de várias fábricas de cimento Portland lo-

foram de $15 \%$ e $2 \%$, respectivamente.

As pozolanas produzidas, nesse trabalho, foram provenientes da calcinação das amostras AZ2 e AZ3 às temperaturas de $150^{\circ} \mathrm{C}, 300^{\circ} \mathrm{C}$ e $500^{\circ} \mathrm{C}$. O procedimento consistiu da secagem das amostras até a constância de massa em estufa a $95^{\circ} \mathrm{C}$. Em seguida, uma quantidade de $400 \mathrm{~g}$ de cada amostra seca de arenito foi submetida à calcinação durante 4 horas na temperatura específica. A Tabela 1 apresenta a nomenclatura das amostras estudadas nesse trabalho.

As amostras dos arenitos zeolíticos peneirados (AZ2 e AZ3) foram submetidas à análise termogravimétrica (ATG) e termodiferencial (ATD). Para as amostras calcinadas (pozolanas), a mineralogia e as fases formadas foram caracterizadas por difração de raios X (DRX), enquanto a atividade pozolânica foi avaliada pelos tradicionais ensaios mecânicos aplicados à argamassas de cal hidratada e cimento Portland. Os resultados desses testes acelerados permitiram a escolha da amostra ideal calizadas no sudeste do Estado do Pará, sudoeste do Maranhão e norte de Tocantins. Essa região não dispõe de depósitos de pozolanas naturais para fabricação de cimento Portland pozolânico, o que induz as fábricas a produzirem cimentos Portland sem a incorporação de adições minerais. Esse tipo de produção, em termos da qualidade do produto, não é favorável, além de elevar em demasia o custo energético e aumentar consideravelmente a emissão de $\mathrm{CO}_{2}$ para a atmosfera.

$\mathrm{O}$ presente trabalho constitui-se em um segundo passo desse programa experimental mais amplo, no qual objetiva-se avaliar a influência do teor de pureza do material (percentual de estilbita e esmectita sobre a massa total) e o efeito da temperatura de calcinação na atividade pozolânica do arenito zeolítico, de modo a determinar qual seria a temperatura ótima que proporciona a maior reatividade e qual seria a fração granulométrica mais adequada para sua produção em escala industrial.

e da temperatura ótima de calcinação.

Para as análises térmicas (ATDATG), foi empregado um equipamento modelo PL Thermal Science com analisador térmico simultâneo STA1000/1500, da Stanton Redcroft Ltda. O equipamento possui um forno cilíndrico vertical e conversor digital acoplado a um microcomputador, utilizando uma faixa de temperatura entre a ambiente e $1100^{\circ} \mathrm{C}$, com taxa de aquecimento de 5 a $20^{\circ} \mathrm{C} /$ min, utilizando, como referência, a alumina calcinada. A taxa de calcinação adotada foi de $10^{\circ} \mathrm{C}$ /minuto.

$\mathrm{Na}$ DRX, foi empregado o método do pó. As análises foram realizadas em difratômetro modelo X'PERT PRO MPD (PW 3040/60) da PANALYTI-

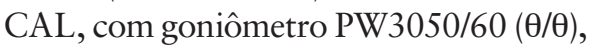
tubo de raios $\mathrm{X}$ cerâmico com anodo de $\mathrm{Cu}\left(\mathrm{Ka}_{1}=1,789 \AA\right)$, modelo PW3373/00, foco fino longo (2200 W- $60 \mathrm{kV})$, filtro $\mathrm{K} \beta$ de Ni. As condições instrumentais utilizadas foram: varredura de 5 a $70^{\circ}$ em $2 \theta$, voltagem de $40 \mathrm{kV}$ e corrente de

\begin{tabular}{c|c|c}
\hline Amostras & Peneira & Temperatura de calcinação $\left({ }^{\circ} \mathrm{C}\right)$ \\
\hline AZ2-1 & $\# 200$ & 150 \\
\hline AZ2-2 & $\# 200$ & 300 \\
\hline AZ2-3 & $\# 200$ & 500 \\
\hline AZ3-1 & $\# 325$ & 150 \\
\hline AZ3-2 & $\# 325$ & 300 \\
\hline AZ3-3 & $\# 325$ & 500 \\
\hline
\end{tabular}


$40 \mathrm{~mA}$, tamanho do passo $0,02^{\circ} \mathrm{em} 2 \theta \mathrm{e}$ tempo/passo de $60 \mathrm{~s}$, fenda divergente de $1 / 8^{\circ}$ e antiespalhamento de $1 / 4^{\circ}$; máscara de $10 \mathrm{~mm}$; amostra em movimentação circular com frequência de 1 rotação/s. Além da análise das amostras in natura, foi realizada a identificação de fases da amostra calcinada a temperaturas compreendidas entre $100^{\circ} \mathrm{C}$ e $1.000^{\circ} \mathrm{C}$, em intervalos de $100^{\circ} \mathrm{C}$, com vistas a observar a ocorrência e/ou formação de novas fases mineralógicas.

A identificação das fases foi feita com o auxílio do Software High Score Plus, também da Panalytical, por comparação do padrão difratométrico com fichas/padrões do Banco de Dados do ICDD-PDF (Internacional Center for Diffraction Data, Powder Diffraction File).

Os equipamentos anteriormente descritos pertencem ao Laboratório de Caracterização Mineral (LCM), do Instituto de Geociências da Universidade Federal do Pará.

A atividade pozolânica do arenito foi determinada, tanto com a cal hidratada, quanto com o cimento Portland CPI-S (NBR 5732). O ensaio que mediu a atividade pozolânica por meio de resultados mecânicos de argamassas com cal hidratada obedeceu às prescrições da NBR 5751. A proporção presente na argamassa, esta constituída de cal hidratada, pozolana (no caso o arenito AZ2 de acordo com procedimento experimental), areia normal e água, foi feita de tal forma que o volume de pozolana fosse o dobro do volume do hidróxido de cálcio (cal hidratada). A quantidade de água a ser adicionada foi aquela necessária à obtenção de uma consistência de $225 \pm 5$ $\mathrm{mm}$, medida na mesa de consistência. As pozolanas consideradas satisfatórias são aquelas que exibem aos 7 (sete) dias valores de resistência à compressão iguais ou superiores a 6,0 MPa.

Para o ensaio mecânico em argamassas com cimento Portland (CPI-S), seguiram-se as diretrizes da NBR 5752, na qual a determinação da atividade pozolânica de um material é função do comportamento mecânico de duas argamassas, preparadas com traço em massa de 1:3 e consistência padronizada de 225 $\pm 5 \mathrm{~mm}$ (mesa de consistência). Para a primeira argamassa, admitida como de referência, foram utilizados apenas cimento, areia normal e água, enquanto que, para a segunda argamassa, parte do volume de cimento $(35 \%)$ foi substituída pela pozolana que se pretende analisar. $\mathrm{O}$ índice de atividade pozolânica com cimento Portland (IAP) é definido como sendo a relação entre as resistências à compressão aos 28 dias da argamassa com pozolana e cimento Portland e a de referência (somente com cimento Portland). Para que um material seja considerado pozolânico, esse índice, normalmente expresso em porcentagem, deve ser superior a $75 \%$. Foram moldadas sete argamassas, sendo uma de referência e as demais com os arenitos AZ2 e AZ3 calcinados nas temperaturas de $150^{\circ} \mathrm{C}, 300^{\circ} \mathrm{C}$ e $500^{\circ} \mathrm{C}$.

No trabalho, foi realizada Análise de Variância (ANOVA) dos resultados de resistência à compressão obtidos com os ensaios de determinação da atividade pozolânica com cal e cimento, com vistas a determinar a significância das variáveis de controle (temperatura e finura) sobre a variável de resposta (resistência à compressão).

\section{Resultados e discussões}

\section{Análise mineralógica das amostras calcinadas}

A Figura 1 mostra os resultados das análises térmicas (ATD-ATG) dos arenitos zeolíticos AZ2 e AZ3. Os comportamentos das curvas termodiferencial e termogravimétrica foram muito semelhantes para as duas amostras, tendo em vista que ambas são constituídas pelas mesmas fases mineralógicas, no caso estilbita e esmectita.

Devido à semelhança no comportamento dos termogramas, as considerações expostas a seguir dizem respeito às duas amostras de arenito. $\mathrm{O}$ primeiro evento térmico ocorre no intervalo de temperatura entre $40^{\circ} \mathrm{C}$ e $129^{\circ} \mathrm{C}$, que corresponde a uma perda de massa de, aproximadamente, $6,50 \%$, no qual ocorre um pico endotérmico a $59^{\circ} \mathrm{C}$. Isto se deve a uma rápida perda de umidade superficial, de fases gasosas adsorvidas na superfície e nos nanoporos das amostras, da água nos vazios da estrutura da estilbita e, principalmente, da perda de água interlamelar da esmectita. Entre 129 e $194^{\circ} \mathrm{C}$, a curva da ATG indica uma perda de massa de 3,50 a 3,70\%; na ATD ocorre um pico endotérmico intenso a $159^{\circ} \mathrm{C}$, que retrata a continuação da perda da água que preenche os canais e cavidades da estilbita. A partir de $200^{\circ} \mathrm{C}$, ocorre uma perda de massa de $7,80 \%$, que se pode atribuir, em grande parte, à perda da água de constituição da estrutura cristalina da estilbita e, em menor proporção, à perda das hidroxilas da esmectita. $\mathrm{Na}$ temperatura de $847^{\circ} \mathrm{C}$, na

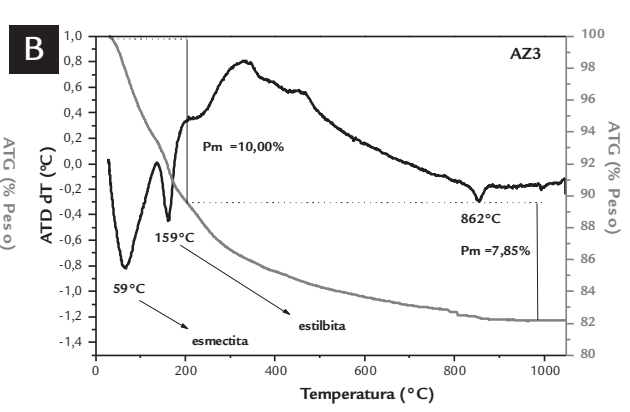

amostra AZ2, e de $862^{\circ} \mathrm{C}$, na amostra AZ3, ocorreu um pico endotérmico devido à destruição do retículo cristalino da esmectita. Contudo não se observou, na $\mathrm{ATD}$, o pico endotérmico referente à remoção das hidroxilas da esmectita, que, normalmente, ocorre entre 400 e $700^{\circ} \mathrm{C}$ NBR 12653.

Os difratogramas de raios $X$ das amostras AZ2-1, AZ2-2, AZ2-3 e AZ31, AZ3-2 e AZ3-3 são mostrados na Figura 2. Nas amostras calcinadas a $150^{\circ} \mathrm{C}$ e $300^{\circ} \mathrm{C}$, independentemente do tipo de arenito, AZ2 ou AZ3, a composição mineralógica é constituída por quartzo, estilbita e esmectita. No caso da estilbita, a melhor ficha desse mineral no ICDDPDF é a 44-1479. Outras zeólitas podem

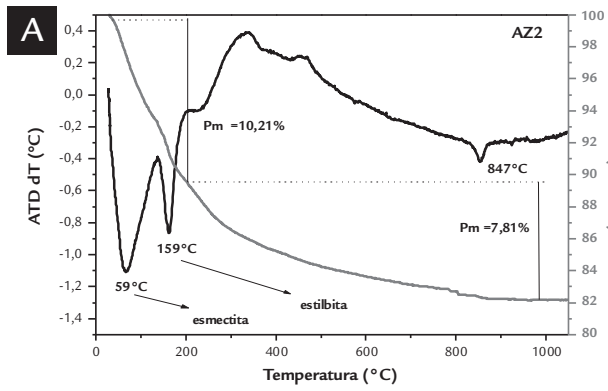

Figura 1

ATD/ATG do arenito zeolítico.

A) ATD/ATG do arenito AZ2.

B) ATD/ATG do arenito AZ3. 
estar presentes, em pequenas quantidades, como laumontita e heulandita, sugeridas a partir da presença apenas do pico principal de cada uma (Picanço et al., 2011). Em relação à esmectita, a mesma foi identificada nos difratogramas de todas as amostras calcinadas a $150^{\circ} \mathrm{C}$ e $300^{\circ} \mathrm{C}$ por uma banda amorfa, localizada a aproximadamente $7^{\circ} 2 \theta$, representando o espaçamento interlamelar $\left(\mathrm{d}_{001}\right)$, em torno de $15 \AA$ (Figura 2). Trabalhos anteriores já descreveram a presença de esmectita associada aos arenitos zeolíticos da Formação Corda e mostraram que se trata de uma montmorilonita, identificada após separação da fração-argila e análise por DRX das lâminas orientadas (seca ao ar, glicolada e aquecida a $550^{\circ} \mathrm{C}$ ), além da análise do pico (060) (Rezende \& Angélica, 1999).

Figura 2

Difratogramas das amostras de arenito zeolítico.

\section{Avaliação da atividade pozolânica}

Nas Tabelas 2 e 3, são mostrados os resultados do ensaio de determinação do IAP com a cal hidratada e cimento Portland, respectivamente. Para as argamassas com cal hidratada, a amostra que apresentou melhor resultado foi a AZ2-3, calcinada a $500^{\circ} \mathrm{C}$, alcançando a resistência à compressão de $5,83 \mathrm{MPa}$, valor muito próximo do limite mínimo de 6,00 $\mathrm{MPa}$, estipulado pela NBR 5751 , para que um material seja considerado pozolânico.

As demais amostras, calcinadas a temperaturas inferiores, 150 e $300^{\circ} \mathrm{C}$, não apresentaram reatividade suficiente para alcançar o limite mínimo de resistência à compressão. Atribui-se isto ao fato de essas temperaturas não ocasionarem a destruição completa das estruturas cristalinas da estilbita e esmectita, estando, ainda, esses minerais com a estrutura
À medida que se aumentou a temperatura de calcinação, ocorreu a diminuição da intensidade dos picos da estilbtia e da esmectita nas amostras AZ2 e AZ3, em decorrência da destruição parcial e gradativa das estruturas cristalinas. Concomitantemente a esse comportamento, observou-se o aumento na intensidade do pico principal do quartzo, em decorrência do aumento relativo de sua concentração nas amostras. Nas temperaturas de $150^{\circ} \mathrm{C}$ e $300^{\circ} \mathrm{C}$, como era esperado, não houve nenhuma alteração na estrutura cristalina da esmectita, ocorrendo, apenas a remoção da água intermelar a $59^{\circ} \mathrm{C}$, conforme visto na análise térmica.

À temperatura de $300^{\circ} \mathrm{C}$, ocorreu uma redução da intensidade dos picos da estilbita, mas o seu desaparecimento ve- rificou-se somente a $500^{\circ} \mathrm{C}$. A destruição estrutural da estilbita, em decorrência, principalmente, da remoção da água presente na estrutura cristalina, ocorre para temperaturas superiores a $200^{\circ} \mathrm{C}$, o que explica porque no difratograma a $300^{\circ} \mathrm{C}$ parte do retículo cristalino da zeolita ainda permanece preservado. $\mathrm{Na}$ temperatura de $500^{\circ} \mathrm{C}$, em ambos os grupos de arenitos zeolíticos (AZ2 e AZ3), as estruturas cristalinas, tanto da estilbita, quanto da esmectita, foram destruídas, permanecendo, apenas, o quartzo como mineral residual. No caso da esmectita, o que ocorre é uma reordenação da estrutura cristalina à temperatura de $500^{\circ} \mathrm{C}$, visto que ocorre, apenas, a remoção da água interlamelar e perda de parte das hidroxilas do retículo cristalino (Souza Santos, 1992).

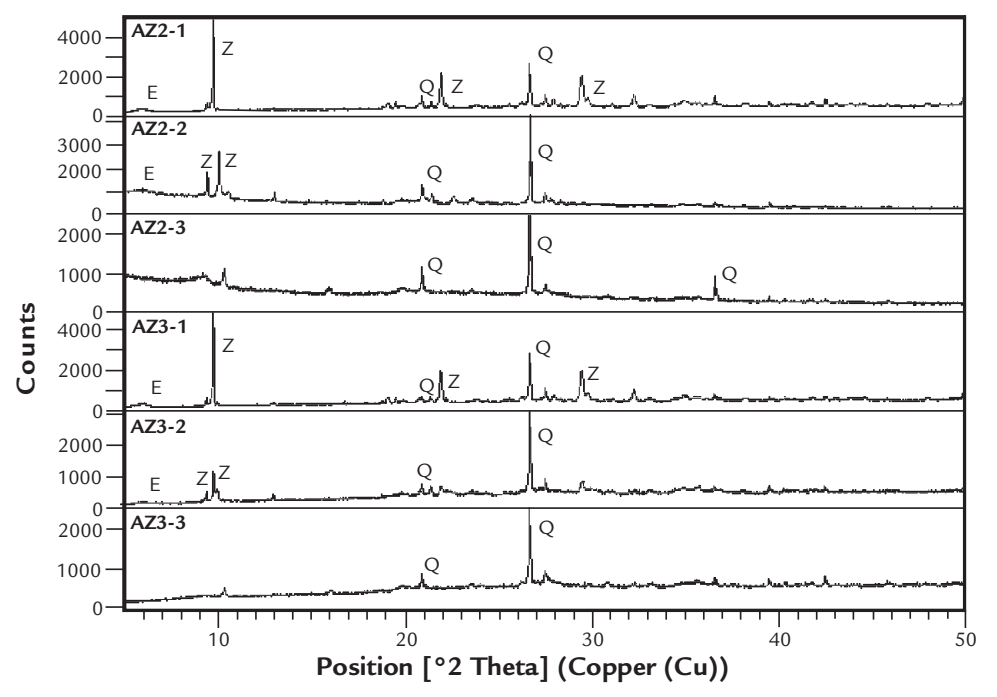

cristalina preservada nos arenitos, o que reduz a reatividade, conforme visto no trabalho de investigação preliminar com arenito não calcinado (Picanço et al., 2011). Os valores de resistência à compressão das amostras calcinadas a 150 e $300^{\circ} \mathrm{C}$ situaram-se entre 3,84 e 5,35 $\mathrm{MPa}$, valores estes similares à resistência de 5,10 MPa da argamassa de cal hidratada moldada com o arenito AZ2 não calcinado (Picanço et al., 2011).

A diferença entre essas menores temperaturas e a de $500^{\circ} \mathrm{C}$, conforme observado na DRX e na ATD, é que, nessa última, ocorre a destruição estrutural de grande parte da estilbita e da esmectita, em decorrência da remoção, tanto da água presente nos vazios da estilbita, quanto daquela constituinte da estrutura cristalina e da remoção da água interlamelar e de parte das hidroxi- las na esmectita.

Apesar de os valores de resistência à compressão, para a temperatura de $500^{\circ} \mathrm{C}$, terem sido, numericamente, superiores, esses valores não são, estatisticamente, significativos, conforme foi observado na ANOVA. Ambas as variáveis de controle, temperatura e finura, não influenciaram, significativamente, a resistência à compressão. Assim não se observou uma interação entre essas duas variáveis. Contudo observa-se uma tendência de ocorrer o aumento na resistência à compressão com o aumento da temperatura, fato este já comentado anteriormente.

Nos ensaios com argamassas de cimento Portland, o comportamento foi, em parte, semelhante ao das misturas com cal hidratada. As amostras calcinadas a $500^{\circ} \mathrm{C}$, tanto a $\mathrm{AZ2}$, quanto a 


\begin{tabular}{c|c|c|c|c}
\hline \multirow{2}{*}{ Amostras } & \multicolumn{2}{|c|}{ Resistência à compressão simples (MPa) } & \multirow{2}{*}{ Média } \\
\cline { 2 - 4 } & $\mathbf{1}$ & $\mathbf{2}$ & $\mathbf{3}$ & \\
\hline AZ2-1 $\left(\# 200-150^{\circ} \mathrm{C}\right)$ & 3,87 & 3,62 & 4,02 & 3,84 \\
\hline AZ2-2 $\left(\# 200-300^{\circ} \mathrm{C}\right)$ & 5,76 & 4,59 & 4,94 & 5,10 \\
\hline AZ2-3 $\left(\# 200-500^{\circ} \mathrm{C}\right)$ & 5,65 & 5,50 & 6,32 & 5,83 \\
\hline AZ3-1 $\left(\# 325-150^{\circ} \mathrm{C}\right)$ & 5,40 & 5,50 & 5,15 & 5,35 \\
\hline AZ3-2 $\left(\# 325-300^{\circ} \mathrm{C}\right)$ & 4,19 & 4,27 & 4,58 & 4,35 \\
\hline AZ3-3 $\left(\# 325-500^{\circ} \mathrm{C}\right)$ & 4,08 & 4,04 & 4,05 & 4,06 \\
\hline
\end{tabular}

\begin{tabular}{c|c|c|c|c|c|c}
\hline \multirow{2}{*}{ Argamassa } & \multicolumn{3}{|c|}{$\begin{array}{c}\text { Resistência à compressão } \\
\text { simples (MPa) }\end{array}$} & \multirow{2}{*}{ Média } & \multirow{2}{*}{$\begin{array}{c}\text { I.A.P. } \\
\text { CP(\%) }\end{array}$} & \multirow{2}{*}{ a/c } \\
\cline { 2 - 4 } & $\mathbf{1}$ & $\mathbf{2}$ & $\mathbf{3}$ & & & \\
\hline Argamassa de Referência & 35,00 & 29,65 & 35,00 & 33,22 & - & 0,63 \\
\hline AZ2-1 (\#200 - $\left.150^{\circ} \mathrm{C}\right)$ & 18,80 & 18,95 & 18,59 & 18,78 & 56,54 & 1,02 \\
\hline AZ2-2 $\left(\# 200-300^{\circ} \mathrm{C}\right)$ & 22,72 & 23,33 & 23,48 & 23,18 & 69,77 & 0,99 \\
\hline AZ2-3 $\left(\# 200-500^{\circ} \mathrm{C}\right)$ & 25,88 & 23,89 & 24,45 & 24,74 & 74,48 & 0,97 \\
\hline AZ3-1 $\left(\# 325-150^{\circ} \mathrm{C}\right)$ & 21,76 & 18,49 & 20,07 & 20,11 & 60,53 & 1,01 \\
\hline AZ3-2 $\left(\# 325-300^{\circ} \mathrm{C}\right)$ & 24,66 & 24,91 & 23,33 & 24,30 & 73,16 & 0,95 \\
\hline AZ3-3 $\left(\# 325-500^{\circ} \mathrm{C}\right)$ & 28,68 & 28,22 & 28,88 & 28,59 & 86,08 & 0,94 \\
\hline
\end{tabular}

AZ3, mostraram reatividade satisfatória, a ponto de proporcionarem IAP iguais ou superiores ao limite mínimo de $75 \%$ estipulado pela NBR 5752. Diferentemente do que ocorreu com as argamassas com cal, o IAP de $86 \%$ da argamassa com AZ3 calcinada a $500^{\circ} \mathrm{C}$ foi superior ao da argamassa com AZ2 calcinado na mesma temperatura, algo satisfatório do ponto de vista pozolânico.

Nas argamassas com cimento Portland, constatou-se uma correlação bem definida entre ambas as variáveis de resposta, temperatura e finura, sobre a atividade pozolânica (resistência à com-

pressão). Independentemente do tipo de arenito, acréscimos, na temperatura de calcinação, ocasionaram incrementos proporcionais na atividade pozolânica, o que não foi constatado nas argamassas com cal hidratada. Independentemente da temperatura, acréscimos significativos foram observados com o aumento da finura do material.

$\mathrm{Na}$ Figura 3, constatam-se esses comportamentos. Percebe-se, ainda, que não há interação significativa dessas variáveis de controle, tendo em vista o paralelismo das curvas. Apesar de a ANOVA indicar que há diferenças significativas

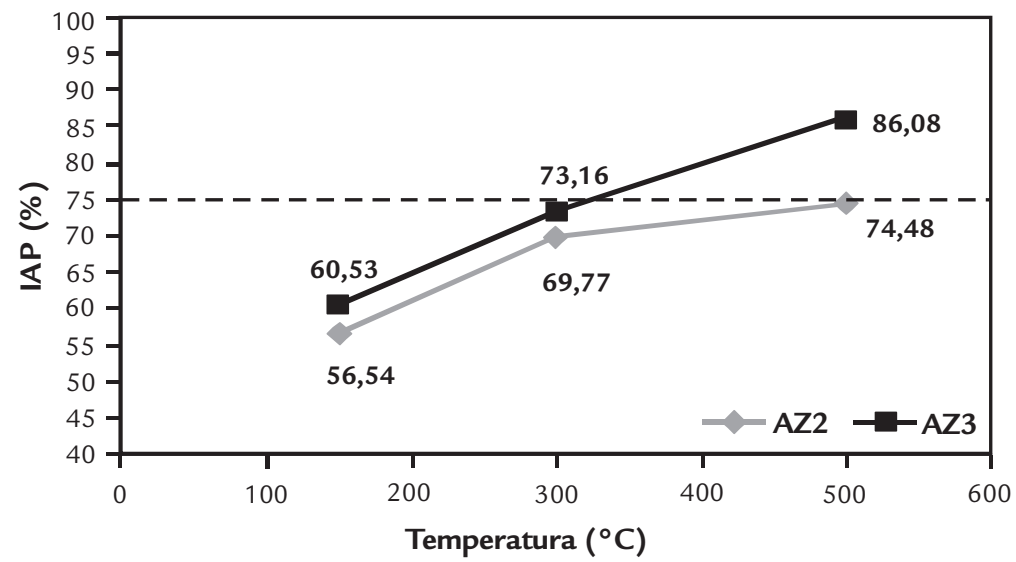

\section{Conclusões}

- O material mais apropriado para a produção do arenito zeolítico é aquele passante na peneira \#200, visto que não houve diferenças significativas na composição mineralógica dessa amostra em relação àquela passante na peneira \#325. Além dis- to, o percentual de aproveitamento do material passante, nessa peneira, fica compreendido entre 15 e $17 \%$, bastante superior a $2 \%$ do passante na peneira \#325 e muito próximo do conteúdo zeolítico presente no arenito in natura, em torno de $18 \%$.
Tabela 2

Atividade pozolânica com cal hidratada.

Tabela 3

Atividade pozolânica com cimento Portland CPI-S.

entre a finura e a temperatura, $\mathrm{o}$ arenito mais fino foi calcinado na maior temperatura, no caso o AZ3 - 3 como o material mais reativo. Optou-se pela escolha do AZ2-3 em função de ele ser um material calcinado na maior temperatura e de não ser de granulometria mais fina. A escolha baseou-se, não no critério estatístico, mas, sim, operacional, uma vez que o beneficiamento do arenito na peneira \#325 inviabilizaria a produção, pois apenas $2 \%$ do material seria aproveitado, ao passo que, na peneira \#200, apenas entre 15 e $17 \%$ do arenito seria utilizado na produção da pozolana.

Figura 3

Dependência entre a atividade pozolânica e a temperatura de argamassas de cimento Portland.
- As temperaturas de calcinação de 150 e $300^{\circ} \mathrm{C}$ não proporcionaram reatividade adequada aos arenitos zeolíticos. A atividade pozolânica dos arenitos AZ2 e AZ3 calcinados nessas temperaturas mais baixas não alcançou o limite mínimo estabele- 
cido para emprego como pozolanas. Nas argamassas com cal, os valores de resistência à compressão foram inferiores a 6,00 $\mathrm{MPa}$, enquanto que, nas misturas com cimento Portland, os IAP foram inferiores a $75 \%$. Isto se deve à estrutura parcialmente preservada da estilbita e da esmectita nas amostras calcinadas nessas temperaturas, que não proporcionaram energia suficiente para destruição da estrutura cristalina desses minerais.

- Para as temperaturas de $500^{\circ} \mathrm{C}$, os arenitos zeolíticos AZ2 e AZ3 apresentaram reatividade satisfatória do ponto de vista pozolânico. Nessa temperatura, ocorre a destruição estrutural de grande parte da estilbita e da esmectita. Nas argamassas com cimento Portland, os IAP do AZ2 e AZ3 foram de $75 \%$ e $86 \%$, respec-

\section{Referências bibliográficas}

tivamente. A maior atividade pozolânica do arenito zeolítico AZ3 é atribuída ao peneiramento mais refinado, que proporcionou um aumento na área superficial específica e na finura desse material, e não à maior concentração de estilbita, uma vez que não se constataram, na análise química, diferenças significativas de concentração desse mineral entre os dois arenitos.

- Nas argamassas com cal hidratada, o comportamento foi diferente daquele observado nas misturas com cimento Portland. Somente a mistura de cal e arenito AZ2 calcinado a $500^{\circ} \mathrm{C}$ alcançou a resistência de $6,00 \mathrm{MPa}$, ao passo que o arenito AZ3 não atendeu ao limite mínimo. Atribui-se essa anomalia ao fato de os ensaios de atividade pozolânica com cimento Por- tland serem mais representativos do que aqueles desenvolvidos com a cal hidratada. No sistema com cimento Portland, outras fases estão presentes, como os aluminatos e sulfatos, que interferem na cinética da reação pozolânica, constituindo-se em um sistema muito mais complexo e realístico do que o da cal hidratada.

- Em suma, o arenito zeolítico da bacia do Parnaíba mostrou-se viável para produção de pozolanas, desde que seja selecionado o material passante na peneira \#200 e ativados termicamente a $500^{\circ} \mathrm{C}$. Estudos mais aprofundados são necessários para verificar a influência de outros percentuais de incorporação desse arenito nas propriedades mecânicas e na durabilidade de concretos e argamassas.

ASSOCIAÇÃO BRASILEIRA DE NORMAS TÉCNICAS - ABNT. NBR 12653: Materiais pozolânicos: especificação. Rio de Janeiro, 1992b.

ASSOCIAÇÃO BRASILEIRA DE NORMAS TÉCNICAS - ABNT. NBR 5732: Materiais pozolânicos - determinação da atividade pozolânica com cimento Portland - indice de atividade pozolânica com cimento: método de ensaio. Rio de Janeiro, 1992a.

ASSOCIAÇÃO BRASILEIRA DE NORMAS TÉCNICAS - ABNT. NBR 5751: Materiais pozolânicos - indice de atividade pozolânica com a cal: método de ensaio. Rio de Janeiro, 1992c.

BARATA, M. S. Aproveitamento dos resíduos cauliníticos das indústrias de beneficiamento de caulim da região amazônica como matéria-prima para fabricação de um material de construção (pozolanas). Belém: Programa de PósGraduação em Geologia e Geoquímica, Universidade Federal do Pará, 2007. 396p. (Tese de Doutorado).

JIEXIANG, G., SUREN, T. The application of natural zeolite in China, In: PROCEEDING OF THE INTERNATIONAL CONGRESS ON APPLIED MINERALOGY; ICAM'93, Fremantle, Wester Australia, May, 31/June, 2, 1993.

LUZ, A. B. Zeólitas: propriedades e usos industriais. Rio de Janeiro: CETEM/CNPq, 1995. 35p. (Série Tecnolgia Mineral, 68).

MALHOTRA, V. M., MEHTA, P. K. Pozzolanic and cementitious materials. Ottawa: Advanced Concrete Technology Program: CANMET, 1996, 191p.

MEHTA, K., MONTEIRO, J. P. Concreto: estrutura, propriedade e materiais. São Paulo: Ed. Pini, 1994.

MEIER, W. M. Molecular sieves. Soc. Chem. Ind., London, 1968. 10 p.

MUSTELIER, J. L. C., Geología, Caracterización y Aplicaciones de las rocas zeolíticas Del complejo volcánico de Cabo de Gata (Almería), Universidad Politécnica del Madrid, Escuela Técnica Superior de Ingenieros de Minas, Madrid, 2008, 515 p.

PICANÇO, M. S., ANGÉLICA, R. S., BARATA, M. S. Avaliação preliminar do emprego de arenito zeolítico da região Nordeste do Brasil como material pozolânico para cimento Portland. Cerâmica, 57, p. 467-473, 2011.

REZENDE, N.G.A.M., ANGÉLICA, R.S. Sedimentary Zeolites in Brasil. Mineralogica et Petrografica Acta, v. 42, p.71-82, 1999.

SOUZA SANTOS, P. Ciência e tecnologia de argilas. (2 $2^{\mathrm{a}}$ ed.). São Paulo: Edgard Blücher, 1992. v. 2. 461p.

Artigo recebido em 20 de julho de 2011. Aprovado em 14 de dezembro de 2011. 